\title{
The consumption of alcohol-based handrub during the 2009 influenza pandemic
}

\author{
A Iten ${ }^{1 *}, N_{\text {Vernaz }}^{2}$, M Descombes ${ }^{1}$, C Posfay Barbe ${ }^{3}$, B Martinez De Tejeda Weber ${ }^{4}$, L Kaiser $^{5}$, D Pittet ${ }^{1}$ \\ From International Conference on Prevention \& Infection Control (ICPIC 2011) \\ Geneva, Switzerland. 29 June - 2 July 2011
}

\section{Introduction / objectives}

When the influenza A (H1N1) 2009 pandemic began, the Federal Office of Public Health released and regularly updated recommendations for the Swiss population and healthcare workers. At the University of Geneva Hospitals, the recommendations for patients, staff and visitors were adjusted according to the local epidemiology, hand hygiene and mask practices were reinforced, and screening of the cases and the prescription of the antiviral treatment were performed as indicated.

\section{Methods}

Using interventional time-series analyses, we performed a transfer model with aggregated data on alcohol-based handrub (ABHR) in litres at HUG and the number of confirmed cases of influenza A (H1N1) in Switzerland as an indicator to evaluate the adherence to the recommendations from April 2009 to January 2010 on a weekly basis.

\section{Results}

A statistically significant temporal relationship was found between the ABHR consumption and the number of $\mathrm{H} 1 \mathrm{~N} 1$ cases. Each additional H1N1 case was preceded by an increase of 0.51 ABHR liters at HUG $(\mathrm{P}<0.0001)$ on week earlier. The R2 coefficient was $96 \%$ expressing how close the observed values are to the fitted values generated by the estimated model.

\section{Conclusion}

This study shows that modelling is a useful tool, complementing traditional epidemiologic approaches, can inform policy makers about the adherence to

'Infection Control Program, University of Genva Hospitals, Geneva, Switzerland

Full list of author information is available at the end of the article recommendations and could be used as an indicator in the follow-up of future influenza epidemics.

\section{Disclosure of interest}

None declared.

\section{Author details}

${ }^{1}$ Infection Control Program, University of Genva Hospitals, Geneva, Switzerland. Pharmacy, University of Genva Hospitals, Geneva, Switzerland. ${ }^{3}$ Department of Pediatrics, University of Genva Hospitals, Geneva, Switzerland. ${ }^{4}$ Department of Obstetrics and Gynecology, University of Genva Hospitals, Geneva, Switzerland. ${ }^{5}$ Central Laboratory of Virology, University of Genva Hospitals, Geneva, Switzerland.

Published: 29 June 2011

\section{doi:10.1186/1753-6561-5-S6-P105}

Cite this article as: Iten et al:: The consumption of alcohol-based handrub during the 2009 influenza pandemic. BMC Proceedings 20115 (Suppl 6):P105.

\section{() Biomed Central}

Submit your next manuscript to BioMed Central and take full advantage of:

- Convenient online submission

- Thorough peer review

- No space constraints or color figure charges

- Immediate publication on acceptance

- Inclusion in PubMed, CAS, Scopus and Google Scholar

- Research which is freely available for redistribution 